\title{
Cerebrovascular High-Flow Bypass for Skull Base Pathologies
}

\section{Wanibuchi $\mathbf{M}^{*}$ and Mikuni $\mathbf{N}$}

Department of Neurosurgery, Sapporo Medical University School of Medicine, Japan

Cerebral bypass surgery is classified as low-flow and high-flow. The low-flow bypass includes the superficial temporal artery (STA) -middle cerebral artery (MCA) anastomosis, first performed by Dr. Yasargil [1] for a patient with a carotid artery occlusion. It is estimated that the low-flow donor vessels provide less than $50 \mathrm{~mL} / \mathrm{min}$ blood flow to the cerebral artery [2]. This low-flow bypass is performed for patients harboring brain ischemia and alterations in brain metabolism due to impaired blood flow. On the other hand, the high-flow bypass is a more reliable procedure for acquiring enough flow volume if a large parent artery is sacrificed. The primary candidate donors of the high-flow graft, providing a blood flow greater than $50 \mathrm{~mL} / \mathrm{min}$, are the saphenous vein (SV) and the radial artery (RA). The first highflow bypass using the SV graft from the common carotid artery to the intracranial ICA was performed by Lougheed et al. [3]. This extracranial-intracranial (EC-IC) high-flow bypass using the SV graft has been applied for the treatment of unclipable aneurysms. Dr. Sundt et al. [4] pioneered this procedure, which was also developed by Dr. Spetzler et al. and Dr. Sekhar et al. [2,4-16]. The EC-IC bypass technique was adapted for the IC-IC bypass, such as the intracranial petrous-to-supraclinoid ICA bypass. The SV graft is extracted from the upper or lower leg, depending on the uniform caliber of the SV with respect to the recipient artery. The SV graft is easy to harvest and the scar of the skin incision may be hidden by the trousers or skirt. The RA graft is easy to identify because the pulsation of the RA is felt at the lateral side of the wrist and the medial side of the cubital fossa. In addition, kinking or torsion of the RA does not tend to occur due to its wall thickness composing of 3 layers.

The majority of the intracranial skull base lesions requiring the high-flow bypass consist of giant paraclinoid ICA aneurysms and cavernous meningiomas [11,13,17-19]. The use of high-flow bypass for those pathologies has gradually declined since alternative treatments including tube stent or radiosurgery have been developed. A balloon test occlusion (BTO) is pre-operatively performed to assess the requirements of the bypass procedure. It is evident that the BTO has become an important reference of diagnosis. The BTO should be performed with neurological monitoring assistance, and cerebral blood flow analysis using perfusion computed tomography scan or single-photon emission computed tomography. However, BTO is not definite to judge the requirement of bypass grafts because the method leads to false negative case [20]. The patency of the high-flow graft was more than $95 \%$ [2]. The morbidity and mortality rates accompanying the surgery were $7 \%$ and $2 \%$, respectively [2,17]. Development of physiological evaluation of vascular reserve and refinement of microsurgical techniques and devices has allowed the surgical procedure to be relatively safe. Nonetheless, prognosis of the original pathologies and the indication of the high-flow bypass surgery should be carefully considered.

\section{References}

1. Yasargil MG (1969) Anastomosis between Superficial Temporal Artery and a Branch of the Middle Cerebral Artery. Georg Thieme Verlag, Stuttgart

2. Sekhar LN, Natarajan SK, Ellenbogen RG, Ghodke B (2008) Cerebral revascularization for ischemia, aneurysms, and cranial base tumors. Neurosurgery 62: 1373-1408.
3. Lougheed WM, Marshall BM, Hunter M, Michel ER, Sandwith-Smyth H (1971) Common carotid to intracranial internal carotid bypass venous graft. Technical note. J Neurosurg 34: 114-118.

4. Sundt TM $3^{\text {rd }}$ and Sundt TM Jr (1987) Principles of preparation of vein bypass grafts to maximize patency. J Neurosurg 66: 172-180.

5. Sundt TM Jr, Piepgras DG, Marsh WR, Fode NC (1986) Saphenous vein bypass grafts for giant aneurysms and intracranial occlusive disease. J Neurosurg 65: 439-450.

6. Sundt TM Jr., Piepgras DG, Houser OW, Campbell JK (1982) Interposition saphenous vein grafts for advanced occlusive disease and large aneurysms in the posterior circulation. J Neurosurg 56: 205-215.

7. Spetzler RF, Fukushima T, Martin N, Zabramski JM (1990) Petrous carotidto-intradural carotid saphenous vein graft for intracavernous giant aneurysm tumor, and occlusive cerebrovascular disease. J Neurosurg 73: 496-501.

8. Sekhar LN, Sullivan BJ (1999) Hypothermic circulatory arrest in neurovascular surgery: evolving indications and predictors of patient outcome. Neurosurgery 44: 686-687.

9. Sekhar LN, Sen CN, Jho HD (1990) Saphenous vein graft bypass of the cavernous internal carotid artery. J Neurosurg 72: 35-41.

10. Sekhar LN and Patel SJ (1993) Permanent occlusion of the internal carotid artery during skull-base and vascular surgery: is it really safe? Am J Otol 14 421-422.

11. Sekhar LN and Kalavakonda C (2002) Cerebral revascularization for aneurysms and tumors. Neurosurgery 50: 321-331.

12. Sekhar LN, Duff JM, Kalavakonda C, Olding M (2001) Cerebral revascularization using radial artery grafts for the treatment of complex intracranial aneurysms: techniques and outcomes for 17 patients. Neurosurgery 49: 646-658.

13. Sekhar LN, Chandler JP, Alyono D (1998) Saphenous vein graft reconstruction of an unclippable giant basilar artery aneurysm performed with the patient under deep hypothermic circulatory arrest: technical case report. Neurosurgery 42: 667-672.

14. Sekhar LN, Bucur SD, Bank WO, Wright DC (1999) Venous and arterial bypass grafts for difficult tumors, aneurysms, and occlusive vascular lesions: evolution of surgical treatment and improved graft results. Neurosurgery 44: 1207-1223.

15. Lawton MT and Spetzler RF (1996) Internal carotid artery sacrifice for radical resection of skull base tumors. Skull Base Surg 6: 119-123.

16. Lawton MT, Hamilton MG, Morcos JJ, Spetzler RF (1996) Revascularization and aneurysm surgery: current techniques, indications, and outcome. Neurosurgery 38: 83-92.

17. Bulsara KR, Patel T, Fukushima T (2008) Cerebral bypass surgery for skul base lesions: technical notes incorporating lessons learned over two decades. Neurosurg Focus 24: E11.

18. Hadeishi H, Yasui N, Okamoto Y (1996) Extracranial-intracranial high-flow bypass using the radial artery between the vertebral and middle cerebra arteries. Technical note. J Neurosurg 85: 976-979.

*Corresponding author: Masahiko Wanibuchi, Department of Neurosurgery, Sapporo Medical University School of Medicine, South 1, West 16 Chuo-ku Sapporo Hokkaido 060-8543, Japan, Tel: +81-11-611-2111; Fax: +81-11-614-1662; E-mail: wanibuti@sapmed.ac.jp

Received May 13, 2013; Accepted August 14, 2013; Published August 16, 2013

Citation: Wanibuchi M, Mikuni N (2013) Cerebrovascular High-Flow Bypass for Skull Base Pathologies. J Vasc Med Surg 1: 113. doi: 10.4172/2329-6925.1000113

Copyright: (C) 2013 Wanibuchi M, et al. This is an open-access article distributed under the terms of the Creative Commons Attribution License, which permits unrestricted use, distribution, and reproduction in any medium, provided the original author and source are credited. 
Citation: Wanibuchi M, Mikuni N (2013) Cerebrovascular High-Flow Bypass for Skull Base Pathologies. J Vasc Med Surg 1: 113. doi: 10.4172/23296925.1000113

Page 2 of 2

19. Mohit AA, Sekhar LN, Natarajan SK, Britz GW, Ghodke B (2007) Highflow bypass grafts in the management of complex intracranial aneurysms. Neurosurgery 60: 105-122.
20. Linskey ME, Jungreis CA, Yonas H, Hirsch WL Jr, Sekhar LN, et al. (1994) Stroke risk after abrupt internal carotid artery sacrifice: accuracy of preoperative assessment with balloon test occlusion and stable xenon-enhanced CT. AJNR Am J Neuroradiol 15: 829-843. 